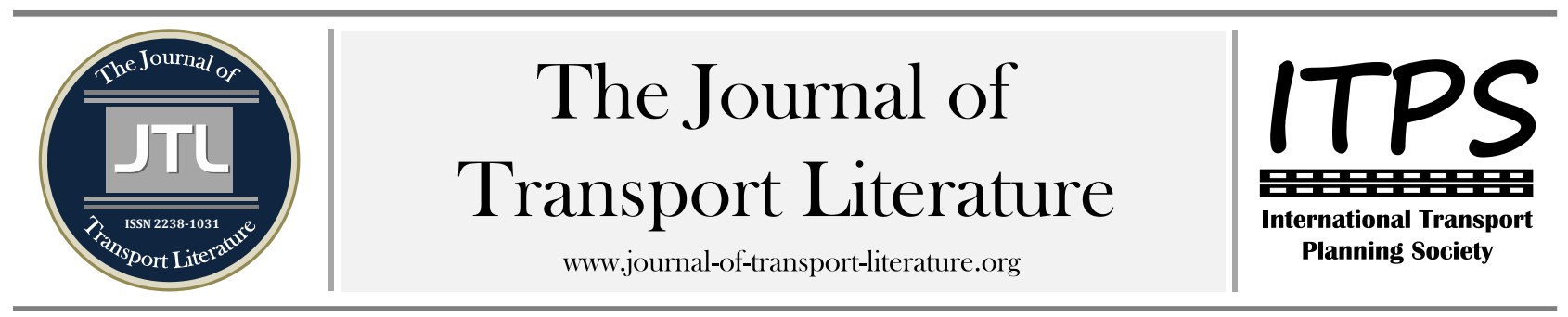

\title{
Segurança de pedestres em rotatórias urbanas
}

\author{
Johnny Vieira de Souza+; Archimedes Azevedo Raia Jr;
} Universidade Federal de São Carlos - UFSCar, São Carlos, Brasil

\section{Article Info}

Palavras-chave:

Rotatórias

Pedestres

Engenharia de Tráfego

Geometria de Vias

Vias Urbanas

Submitted 29 Jun 2015;

received in revised form 5 Jul 2015;

accepted 12 Jul 2015

Licensed under

Creative Commons

CC-BY 3.0 BR.

\section{Resumo}

Dentre as várias técnicas para abrandar as causas perniciosas provenientes dos cruzamentos no trânsito estão as rotatórias, dispositivos viários de melhor eficiência e menor custo, que têm como finalidade simplificar a interseção, para que o tráfego que se ali interage tenha um desenrolar seguro. Embora venha sendo muito utilizada no trânsito urbano brasileiro, as rotatórias priorizam o veículo motorizado devido à falta de infraestrutura, seja por opção ou carência de conhecimento técnico, para que principalmente o pedestre tenha igual segurança. Para aferir quais são os indicadores que levam a esta situação nos dispositivos, foram utilizados cinco rotatórias em São José do Rio Preto e cinco em São Carlos e proposto um confronto de conceitos técnicos entre especialistas, através do método AHP, literatura especializada e realidade constatada in loco, para verificar possíveis similaridades e diferenças existentes entre definições, conceitos e opções. Chegou-se à conclusão que a literatura e os especialistas no assunto defendem os pedestres como prioridade de projeto, implantação, infraestrutura e manutenção, entretanto os dispositivos não estão aptos a segurança dos mesmos.

+ Corresponding author. Rua Manoel Caparroz Lopes, 463 - Jd. Caparroz - CEP 15050-410 - São José do Rio Preto SP - Brasil.

E-mail address: johnny.vs@hotmail.com.

\section{Introdução}

0 acréscimo significativo dos automóveis que circulam pelas redes viárias e geram conflitos para a área urbana de modo geral, tem como fatores propulsores a distância, aliados ao incentivo do governo federal ao uso do automóvel particular através de linhas de créditos para o cidadão e redução de impostos, tendo em contrapartida a falta de investimentos no transporte público coletivo e a disparidade na relação custo-benefício. 0 governo municipal procura, fazer intervenção com melhor benefício-custo possível nas malhas urbanas na tentativa de solucionar ou ao menos amenizar os problemas citados com o investimento disponível, máxima fluidez e segurança (TORRES, 2010). Os cruzamentos são pontos de acumulação de acidentes, com excesso de veículos, que causam gargalos ou grandes congestionamentos e, do ponto de vista da segurança do pedestre, é onde há travessias e, consequentemente, atropelamentos (QUEIROZ, 2003).

Com o aumento na frota veicular, a Engenharia de Tráfego criou várias tipologias geométricas, dentre os sistemas de melhor eficiência e menor custo estão as rotatórias, que têm como objetivo a interseção, para que o tráfego que se ali interage tenha um desenrolar seguro, com pequenos tempos de espera. Embora na atualidade venha sendo muito utilizada no trânsito urbano mundial e brasileiro, na maioria dos casos, as rotatórias são elementos geométricos que priorizam ou monopolizam o trânsito veicular motorizado (DER-SC, 2000). De modo geral, os pedestres são mais frágeis do que os veículos automotores, portanto são expostos ao maior risco de morte; tais consequências trazem números de acidentes e despesas particulares e ao governo. São diversos os custos, dentre os quais pode-se citar: resgate de vítimas, internações, cirurgias ou ao cidadão diretamente através de sequelas físicas e ou tratamentos médicos longos e, consequentemente, gasto particular financeiro hospitalar, falecimentos, desequilíbrio mental e tratamento médico de familiares, devido a este tipo de perda "inesperada". Segundo Ferraz et al. (2012), um acidente na zona urbana que provoque apenas danos materiais foi estimado, na época, em $R$ \$ 5.461,00, acidentes com vítimas podem chegar a $R \$ 29.231,00$ e com vítimas fatais chegam a $\mathrm{R} \$ 241.320,00$. 0 valor estimado em média por acidente é $\mathrm{R} \$ 14.704,00$. 0 principal e mais frágil dos envolvidos, o pedestre e sua segurança, não têm sido suficientemente abordados nos pontos de conflitos da mobilidade durante as décadas passadas. A falta de orientação e quebra de paradigma cultural sobre as vantagens da caminhada proporcionalmente aos demais envolvidos (veículos automotores) gerou uma grande decadência na caminhada humana nos espaços urbanos sem a finalidade esportiva, principalmente, por vias de maior trânsito, como as coletoras e arteriais.

Segundo SNTMU/MC (2007), um município com população de 250 mil a 500 mil de habitantes possui, em média, 40\% das viagens urbanas (do início ao fim do trajeto) a pé, fato que coloca todos os cidadãos como pedestres no trânsito antes de serem motoristas, motociclistas ou passageiros. A situação é emblemática nos municípios de maior porte populacional, pois possuem em sua malha viária vários "vazios humanos", ou seja, áreas que o pedestre não tem acesso, acesso limitado ou restrito, proibido ou com alta periculosidade, devido à sua exposição ao tráfego automotivo, dentre estes locais estão as rotatórias. Em vista do exposto, esta pesquisa tem como objetivo geral analisar a segurança de pedestres em dispositivos viários do tipo rotatórias, em ambientes urbanos utilizando como instrumentos a pesquisa com especialistas em trânsito (método AHP), estudo observacional e coleta de dados físicos nas rotatórias e revisão da bibliografia especializada. Para tal, serão utilizadas, como estudo de caso, as cidades paulistas de médio portes São José do Rio Preto e São Carlos. Este artigo possui além da introdução, três capítulos além das conclusões, agradecimentos, referências e resumo na língua inglesa. Os 
capítulos são: i) Rotatórias e pedestres no contexto urbano: aborda a relação da caminhada no dispositivo e a inserção da rotatória na malha viária urbana; ii) Método do trabalho: aborda como foi realizada a pesquisa; e iii) Resultados e discussão: apropinqua os resultados obtidos nas pesquisas e estudos de caso com análise crítica.

\section{Rotatórias e pedestres no contexto urbano}

Para Mello (2008), andar é muito mais do que ir do ponto de partida ao ponto de chegada, o pedestre ao caminhar tem um envolvimento com o mobiliário urbano, com a paisagem e com as pessoas. Os deslocamentos de pedestres, principalmente em viagens curtas, representam uma parte fundamental dos deslocamentos de uma área urbana, que devem ser asseguradas pela infraestrutura adequada. Umas das infraestruturas urbanas são as rotatórias, que possuem poucas desvantagens em relação à sua implantação no contexto urbano, porém, uma das maiores está relacionada diretamente com a insegurança do pedestre. A segurança viária também é questão de percepção contra riscos reais, afirmam Stone et al. (2002). Embora a rotatória tenha elementos técnicos que se associam ao trânsito seguro, vários pedestres não têm esta percepção por não haver um controle sobre o direito de passagem, como por exemplo, um semáforo. Segundo Silva e Seco (2004), quando o fluxo de pessoas no cruzamento é considerável, o fato se torna um critério para não implantação da rotatória neste local. A associação entre os passeios e a rotatória é pouco atrativa para o pedestre, já que o seu trajeto é aumentado, devido à preocupação com a segurança do cruzamento, fazendo com que se deva ter, do anel de delimitação ao ponto de travessia (faixa de pedestre) uma distância de $10 \mathrm{~m}$ a $15 \mathrm{~m}$. Uma solução um pouco mais segura para o pedestre impõe-lhe uma distância percorrida muito maior do que de um cruzamento convencional, fato que induz o pedestre a procurar percorrer a menor distância entre os pontos desejáveis através da ilha central, expondo-o a acidentes, o que seria tecnicamente inadmissível (STONE et al., 2002). Uma maneira de impedir o trânsito de pedestres pela ilha central é a criação de barreiras físicas através de arbustos de pequeno porte ou uma solução mais técnica e menos natural, como alambrados, muretas ou grades (SILVA e SECO, 2004). As vias de aproximação da rotatória possuem um raio de curvatura (esquina) maior por causa da canalização do fluxo. Este fato traz para o pedestre outra dificuldade; atravessar uma via mais larga e na maioria das vezes de dois sentidos de fluxo. Devido a esta dificuldade, há outro elemento de apoio ao pedestre, a ilha separadora central. Este elemento segrega a via garantindo maior segurança, pois a travessia é realizada em duas etapas (NCHRP, 2011).

Raia Jr. et al. (2008) apontam, por diversas razões, que incluem características físicas e dimensões, as rotatórias podem dificultar a travessia de pedestres com deficiência física, sendo pouco atrativas para o público com limitações físicas ou dificuldades para locomoção. Ainda de acordo com os autores, por não haver um controle de tempo de travessia entre veículos e pedestres, as rotatórias dificultam a confiança na travessia de deficientes visuais, fato que expõe o cidadão com esta dificuldade a acidentes e a insegurança para travessar. Stone et al. (2002) apontam que, pelo fato das rotatórias interligarem na sua grande maioria sentido duplo de direção nas vias de aproximação, isto requer maior atenção do pedestre durante a travessia. Conforme FHWA (2006), quanto maior for a distância da faixa de pedestres em relação à ilha central da rotatória, maior será a segurança da travessia, porém quanto maior for esta distância, maiores serão as chances do pedestre travessar fora da faixa. Este fato se traduz em um grande problema da travessia envolvendo pedestres na rotatória, caminhar mais para realizar a transposição devido à circunferência do dispositivo rotário. Para NCHRP (2011), há quatro áreas que requerem diferentes tratamentos para melhorar os aspetos direcionados à acessibilidade de pedestres nos cruzamentos. Os quatro componentes são: i) Localização da faixa de pedestres; ii) Alinhamento para atravessar; iii) Identificar uma oportunidade (gap) para efetuar a travessia; e iv) Manter o alinhamento durante a travessia. Ainda de acordo com NCHRP (2011), um pedestre que se aproxima de um cruzamento precisa ser capaz de identificar a localização da faixa de pedestres. Para interseções ortogonais padrão, esta é uma tarefa relativamente simples, uma vez que as rampas de acessibilidade e as faixas estão localizadas na vizinhança do canto de interseção, o raio da esquina não é significativo. No entanto, nas rotatórias não existe um ponto distinto de interesse (como o canto), e a falta de padronização da localização das faixas induz a travessia próxima da via circular, fato que expõe o pedestre a maiores riscos de atropelamentos. Stone et al. (2002) afirmam que o maior dilema da segurança dos pedestres na rotatória está na dificuldade de obter dados concretos sobre acidentes e estudos que mostram quais são os efeitos reais do dispositivo, problema este também apontado por Traekratoc (1998) e Raia Jr. et al. (2008). Enfim, a questão da segurança de pedestres em relação às rotatórias tem preocupado a muito pesquisadores. Vários trabalhos têm sido realizados e que, de alguma forma, demonstram alguma preocupação com a segurança de pedestres na transposição de rotatórias, como são os casos de: Daros (1988, 2000), Taekratoc (1998), FWHA (2000), Faria et. al. (1999), Silva (2002), Stone et al. (2002), Silva e Seco (2004, 2008), Raia Jr. et al. (2008), Barbosa (2010) e Torquato (2011). Embora o tema esteja sendo abordado com maior frequência nos últimos anos, pesquisas envolvendo rotatórias e a segurança do pedestre ainda tem sido pouco abordadas por pesquisadores em nível mundial (STONE et al., 2002), e no Brasil a situação é ainda mais crítica (RAIA Jr. et. al., 2008).

\section{Método do trabalho}

Inicialmente, foram abordadas as variáveis que contemplam a segurança viária de pedestres no trânsito, tendo como foco principal, o dispositivo viário, denominado rotatória junto à bibliografia especializada. Após o levantamento foram criadas duas variáveis de análise: 1. Variáveis referentes ao pedestre na via pública, tais como: i) condições das travessias (sinalização viária); ii) pavimentação dos passeios; iii) rampas para acessibilidade; iv) dispositivos que auxiliam a segregação dos espaços destinados ao pedestre (cercas, áreas gramadas); v) mobiliário urbano e arborização nos passeios; e vi) iluminação do passeio público; 2. Variáveis referentes à rotatória inserida no contexto urbano, tais como: i) características geométricas do dispositivo; ii) características das vias de aproximação à rotatória (largura, classificação, quantidade de faixas de rolamento); e iii) características do uso e ocupação no entorno do dispositivo (área mista, predominantemente residencial, comercial ou industrial).

\subsection{Vertente 1 = Aplicação do método Processo Analítico Hierárquico (AHP)}

A avaliação teve como objetivo estabelecer a importância relativa (peso) dos diferentes indicadores propostos para definir um índice de rotatória urbana. Para tanto, estes indicadores foram distribuídos em sete matrizes (temas) e a 
avaliação foi feita entre os indicadores de cada grupo de matrizes (subcritérios), e por último, uma avaliação entre as matrizes que compõem o assunto. A proposta de indicadores se baseou na definição de Mobilidade Sustentável: "uma forma de mobilidade que promova uma igualdade de possibilidades de deslocamentos, com facilidades de acesso às diversas atividades de uma região, promovendo a cidade mais humana". Os elementos técnicos foram agrupados em sete matrizes principais e vários subcritérios. 0 pesquisado (especialista em engenharia urbana ou áreas relacionadas) alocou pesos predefinidos para cada matriz e subcritério de acordo com o seu conhecimento e opinião. 0 agrupamento será feito pelo grau de relação ou funcionalidade entre os elementos e diferentes áreas avaliativas de um mesmo elemento.

Foram escolhidos os técnicos / profissionais que estão ligados diretamente aos atores envolvidos na Engenharia de Tráfego, seja na etapa de projeto, implantação, manutenção ou pesquisa; estes profissionais deveriam atender a um ou mais dos itens, tais como: i) Profissionais com formação acadêmica em Engenharia ou Arquitetura e Urbanismo; ii) Sem ou com formação acadêmica e que tenha experiência profissional em órgãos gestores de trânsito; iii) Professores (Mestres e Doutores) que pesquisam e ensinam sobre trânsito, transportes e ou segurança viária. Os pesquisadores tiveram 15 dias para responderem via internet a planilha devidamente preenchida. Após a recepção de todas as planilhas, os dados passaram por processo de verificação de consistência, sendo posteriormente agrupados para serem confrontados, discutidos e comparados com a segunda vertente da pesquisa, ou seja, com os dados obtidos em pesquisa de campo.

\subsection{Vertente 2 = Estudos de Caso}

Após a definição dos principais elementos que contemplam a implantação, manutenção e operação das rotatórias, obtidos através das respostas dos especialistas, foram levantadas as questões de envolvimento entre pedestres e rotatórias nos municípios escolhidos (São José do Rio Preto SP e São Carlos SP), que possuem uma grande frota proporcionalmente ao número de habitantes (taxa de motorização). Foram escolhidas cinco rotatórias para os estudos de caso que atendessem, pelo menos, a três critérios básicos. Os critérios para a escolha das rotatórias estão baseados em: i) Rotatórias urbanas de faixa única ou dupla; ii) Importância da rotatória na malha viária (pelo menos uma das vias de aproximação deveria ser arterial e/ou coletora); iii) Proximidade das rotatórias a parques, praças, escolas, terminais ou polos geradores de viagens (estabelecimentos comerciais, de serviços, educacionais, de lazer, etc., que assegurassem um volume razoável de pedestres nas rotatórias). A coleta de dados foi embasada em três grupos, da seguinte forma: a) Entorno da rotatória - i) Mapeamento das rotatórias em relação ao sistema viário do município; ii) Uso e ocupação do solo no entorno, diâmetro de $150 \mathrm{~m}$ a partir da ilha central; iii) A escolha deste diâmetro se deu pela relação direta dos usuários/moradores dos prédios próximos (dentro desta área) com a rotatória. (usuários/moradores de edificações mais distantes podem utilizar outras rotas de acesso sem passar pelo dispositivo); e iv) Hierarquização das vias de aproximação. b) Rotatória - i) Dimensões geométricas da rotatória (ilha central, via de circulação e passeios); ii) Mobiliário urbano (lixeiras, pontos de ônibus, bancos, floreiras); iii) Postes de iluminação; iv) Arborização; v) Acessibilidade e mobilidade; c) Sinalização de trânsito; (rotatória e distância máxima de 50m em cada via de aproximação); vi) Faixas de sinalização do solo; vii) Tipo de pavimento dos passeios; e viii) Levantamento fotográfico com identificação das fotos em planta; d) Estatísticas - i) Contagem de volume de tráfego de $1 \mathrm{~h}$ pico (manhã, tarde ou noite) em um dia típico de uma semana típica (pedestres e veículos); e ii) Pesquisa junto à prefeitura, polícia e entidades sobre acidentes nos locais da pesquisa. Após a recepção dos dados das rotatórias e das pesquisas, estes foram tratados para posteriormente serem confrontados com os resultados da vertente 1.

\subsection{Finalização da Pesquisa}

Após o processamento de todas as informações coletadas, os dados foram confrontados e criticados, fornecendo subsídios para a discussão da problemática da mobilidade, segurança e acessibilidade dos pedestres nas rotatórias, possibilitando a identificação de medidas favorecedoras nas áreas de políticas públicas, planejamento urbano e segurança viária. Os resultados permitiram observar duas situações: i) Visão ampla: A rotatória como dispositivo viário inserido no contexto urbano de mobilidade e espaço; e ii) Visão restrita: 0 elemento técnico inserido para sanar problemas e priorizar um ou mais modos de transporte que dependem de um estudo aprofundado e verbas para a implantação, que dependendo da situação financeira poderá ser descaracterizado na manutenção ou não receber os elementos técnicos para cumprir sua função com segurança. Em síntese, os elementos de geometria, sinalização, iluminação, conservação, arborização, etc., apontados pelos especialistas foram confrontados com a existência ou não destes elementos nas rotatórias tomadas como objetos de estudo. Da mesma forma, pode-se conhecer se existe alguma correlação entre a ausência de elementos essenciais à segurança do pedestre e a ocorrência de acidentes envolvendo-os nas rotatórias estudadas.

\section{Resultados e discussão}

A taxa de pedestres, ou seja, a relação entre o número de pedestres e o número de veículos que trafegam pela rotatória na hora pico manhã, por exemplo, é um importante instrumento de verificação para expor a atratividade de pedestres que circulam pelo dispositivo. As taxas de pedestres em São José do Rio Preto mostraram grande oscilação; a rotatória que obteve a menor taxa de pedestres sobre a quantidade de veículos foi a "Parque do Rio Preto" com 0,6\%, seguida pela "Mini Estação Av. Potirendaba" com 2,6\%, "Shopping Cidade Norte" com 3,9\%, UBS Anchieta com 5,2\% e a maior foi a UPA Jaguaré com 6,1\%. Em São Carlos também foi registrada grande variação no volume de pedestres de um dispositivo para outro. Por outro lado, a rotatória que obteve maior volume de pedestres em quantidade e proporcionalmente de todas as rotatórias avaliadas, incluso as de São José do Rio Preto, foi a CDHU, em São Carlos, com 293 transeuntes (14,5\%) seguidas pelas rotatórias “Praça Itália" (4,3\%), “Carrefour" (3,6\%), “UNICEP” (3,4\%) e “Cardinali” (1\%).

0 estudo observacional realizado nas dez rotatórias resultou em dados preocupantes quanto ao risco de segurança do pedestre nesses dispositivos. Em São José do Rio Preto, em média, mais da metade dos pedestres (51,7\%) atravessam em locais de alta periculosidade e apenas $(21,4 \%)$ em locais considerados como ideais, isto é, de baixo risco. Em São Carlos, a periculosidade é ainda maior, em média, $67,5 \%$ dos pedestres atravessam em locais de alta exposição a riscos de acidentes e apenas 22,3\% em locais considerados como riscos ideais, ou seja, número semelhante a média de São José do Rio Preto. Os altos números associados com o risco na travessia de pedestres, nas rotatórias, poderiam apontar para três vertentes: i) Má localização da faixa de pedestres: referente à localização inadequada das faixas de segurança para pedestres que, na maioria dos casos, estão muito próximas da via circular da rotatória; ii) Falta de conscientização dos pedestres: referente à falta de 
educação e orientação dos pedestres para o trânsito, que atravessam em qualquer lugar simplesmente para diminuir o trajeto desejado; e iii) Falta de barreiras físicas que impeçam a travessia inadequada: referente a falta de elementos físicos que impeçam a travessia de pedestre em locais perigosos. Devido à ausência destes elementos os pedestres têm liberdade para atravessar onde acharem mais conveniente, principalmente, para diminuir a distância de caminhada. Os estudos aqui realizados, considerando as dez rotatórias, permitiram concluir que as localizações dos passeios interferem diretamente na segurança do pedestre, nas rotatórias "UPA Jaguaré", "Shopping Cidade Norte" e "Carrefour", que possuem passeios na ilha central. Nestas rotatórias à exposição a alto risco nas travessias foi alta $(75,2 \%, 47,6 \%$ e 89,7\%, respectivamente).

Em São José do Rio Preto, os números mostraram que, em média, passaram pelas rotatórias 126 pedestres na hora/pico da manhã e cada um deles realiza duas travessias, em média. Outro índice importante é que, em média, 27,4\% dos pedestres não atravessaram pelo dispositivo, pela opção da rota mais segura ou mais curta. Em São Carlos, os números mostraram que, em média, passaram pelas rotatórias 144 pedestres na hora/pico da manhã e cada um realiza 2,54 travessias, em média, número este superior do que o registrado em São José do Rio Preto. Outro índice importante é que, em média, 26,7\% dos pedestres não atravessaram pelo dispositivo viário, seja pela opção da rota mais segura ou curta números similares aos registrados em São José do Rio Preto. Segundo a APATRU (2014), o número de acidentes de qualquer gravidade envolvendo pedestres nas rotatórias abordadas nos estudos de caso de São José do Rio Preto são, em média, iguais a 1,2 por ano. 0s números de acidentes de qualquer gravidade envolvendo pedestres nas rotatórias dos estudos de caso em São Carlos foram maiores do que os registrados em São José do Rio Preto, iguais a 3,0 por ano (Carmo, 2013).

Embora o número de acidentes seja relativamente baixo, cabe salientar que grande parte dos dados acabam sendo subregistrados, principalmente devido a dois aspectos: i) falta de registro da ocorrência (boletim de ocorrência), principalmente os de menor gravidade, e ii) registro da ocorrência de acidente onde consta como referência as vias que envolvem o dispositivo, em vez citar especificamente a rotatória, o que inviabiliza a sua localização geográfica mais precisa.

Todas as matrizes e critérios abordados no método AHP influenciam de alguma forma o projeto, manutenção e operação de uma rotatória urbana, entretanto, com os resultados tratados foi possível mensurar qual foi a principal matriz e consequentemente qual é o critério mais importante segundo os pesquisados. As matrizes de análise foram: i) sinalização, ii) infraestrutura, iii) geometria, topografia e dimensionamentos, iv) modos de transportes, v) iluminação, vi) características do entorno e uso e ocupação do solo, e vii) influências externas ao projeto. Para os pesquisados, a matriz mais importante é a "sinalização", pois, obteve, considerando o comparativo geral de matriz versus matriz, quatro avaliações com maior e duas de igual importância sobre as demais (Gráfico 1 - Figura 1), com média 52\% de maior relevância (Gráfico 2 - Figura 1).
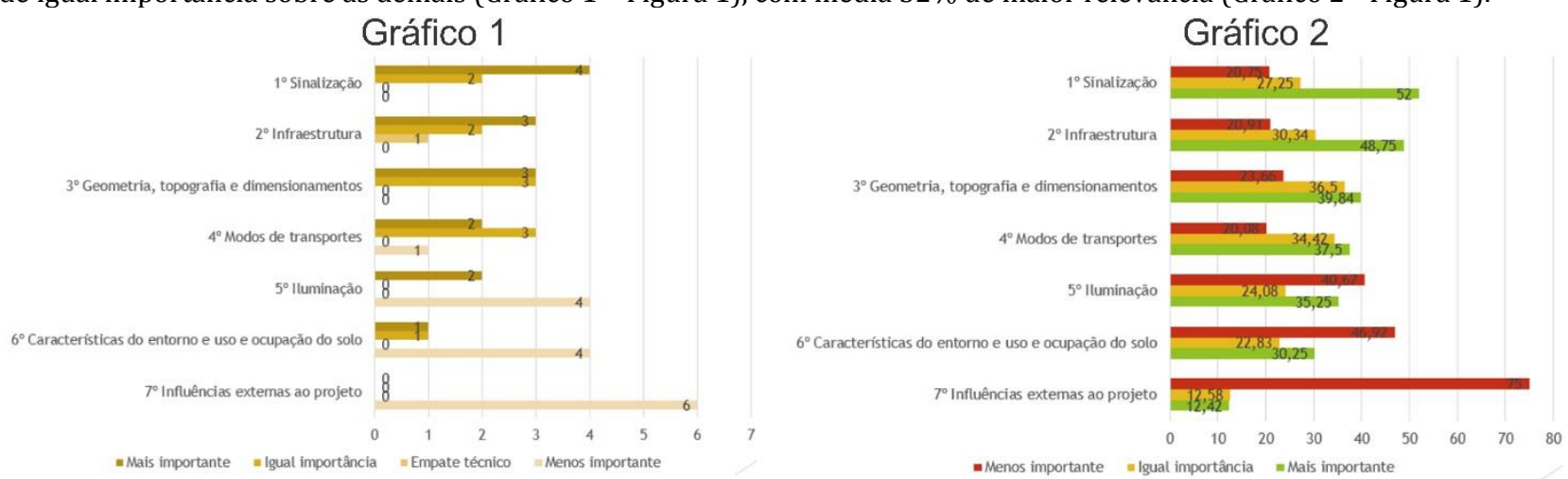

Figura 1 - Ordem de importância dada para as matrizes (resultados em quantidade e porcentagem) comparação de par em par.

0 resultado apontou fato condizente a realidade constatada in loco, pois a sinalização foi o elemento mais presente nos dispositivos, entretanto a prioridade de projeto e infraestrutura para o pedestre apontada no resultado do método AHP contradisse a realidade dos dispositivos.

\section{Conclusão}

O assunto, após os estudos, análises, pesquisas, comparativos e resultados revelou-se como extenso e complexo. Ao analisar a literatura especializada, consultar os técnicos especialistas no assunto (através do Método AHP) e constatar in loco as condições reais de dez rotatórias, pode-se concluir a nível de contradição que os pedestres não possuem infraestrutura (acessibilidade e mobilidade) nos dispositivos, fato que contradiz principalmente os técnicos que afirmam ser o modo a pé, aquele o modo de transporte mais importante.

Embora foram encontrados muitos aspectos contraditórios entre literatura, especialistas e estudos de caso, há exterioridades condizentes como a sinalização, um dos aspectos mais importantes, segundo os especialistas, de modo geral, está presente nos dispositivos, fato que condiz também com a literatura.

Através da coleta do volume de veículos (hora / pico manhã) e análise do uso e ocupação do solo ficou constatado que há relevância entre um e outro assunto que influencia diretamente na quantidade e perfil dos pedestres e veículos transeuntes pelo dispositivo. Através do estudo de volume de "veículos" (incluindo aqui os pedestres), ficou constatado que o volume de pedestres é pouco representativo nas rotatórias estudadas, fato que condiz com a literatura que afirma que o dispositivo é pouco atrativo para pedestres, a exceção é o caso da rotatória CDHU, em São Carlos;

O método AHP mostrou-se eficiente para priorizar e organizar os critérios pré-definidos e encontrar os assuntos de maior importância, entretanto, apesar que a amostragem esteja dentro da quantidade de pesquisadores esperada devido a exemplo de outras pesquisas realizadas, o número de pesquisadores que responderam mostrou-se muito apequenado diante da abordagem e complexidade do assunto.

Devido as dificuldades abordadas, esta pesquisa mostrou-se limitada em alguns resultados devido à falta de instrumentos apropriados, banco de dados estatísticos precisos para melhor suporte e maior confiabilidade em alguns resultados, principalmente envolvendo o volume de veículos hora/pico e quantidade de acidentes. 
As rotatórias são dispositivos viários que estão cada vez mais presentes na malha viária das cidades brasileiras, entretanto ficou explícito que a implantação dos dispositivos está sendo realizada, aparentemente, sem um estudo aprofundado sobre o traçado viário e geométrico das vias existentes, além da falta de infraestrutura voltada ao pedestre. Estes fatores têm gerado grande exposição a acidentes e baixa atratividade de pedestres nas rotatórias.

As rotatórias são dispositivos extremamente técnicos que necessitam de especialistas no assunto para serem implantadas e/ou alteradas, se não for oferecida devida atenção por técnicos podem gerar riscos e transtornos aos veículos e prédios do entorno. Dessa forma, este trabalho pode contribuir para o avanço da literatura sobre o tema, principalmente no Brasil, na medida que procura caracterizar aspectos reais a conceitos e definições teóricos associados ao campo de atuação profissional propriamente dito.

\section{Agradecimentos}

À APATRU pelo fornecimento dos dados.

\section{Referências}

Apatru. (2014). Banco de dados permanente. (Publicação 2014).

Barbosa, G. A. C. (2010). Percepção de risco e comportamento dos pedestres: um estudo exploratório na cidade de Maceió (Dissertação Mestrado). Universidade Federal do Rio de Janeiro, Rio de Janeiro, Brasil.

Carmo, C. L. (2013). Efeitos da configuração urbana na acidentalidade envolvendo pedestres em cidades de porte médio (Dissertação Mestrado). Universidade Federal de São Carlos, São Carlos, Brasil.

Daros, E. J. (1988). Acidentes de trânsito e comportamento humano. In: I Encontro Nacional para Prevenção de Acidentes de Trânsito e Primeiros Socorros ao Acidentado, Sociedade Nordestina de Neurocirurgia, Brasil.

Daros, E. J. (2000) 0 pedestre: 13 condições para torná-lo feliz. Associação Brasileira de Pedestres, São Paulo, Brasil.

Der-sc. (2000). Utilização e configuração de rotatórias em estradas fora de áreas urbanizadas. Departamento de Estradas de Rodagem de Santa Catarina, Florianópolis, Brasil.

Faria, E. O.; Portugal, L. S.; Braga, M. G. C. (1999). Sistema especialista para tratamento de travessias de pedestres. Rio de Janeiro, Brasil.

Ferraz, C.; Raia Jr., A. A.; Bezerra, B.; Bastos, T.; Rodrigues, K. (2012). Segurança Viária. São Carlos: Suprema.

Fhwa. (2000). Roundabouts: an Informational Guide. Department of Transportation, Federal Highway Administration, Turner-Fairbank Highway Research Center, McLean, Virginia: Department of Transportation.

Fhwa. (2006). Pedestrian Access to Roundabouts: assessment of motorists' yielding to visually impaired, pedestrians and potential treatments, to improve access. Department of Transportation, Federal Highway Administration, Virginia, USA: DoT.

Mello, M. B. A. (2008). Estudo das variáveis que influenciam o desempenho das travessias de pedestres sem semáforos (Dissertação Mestrado). Universidade Federal do Rio de Janeiro, Rio de Janeiro, Brasil.

Nchrp. (2011). Crossing solutions at roundabouts and channelized turn lanes for pedestrians with vision disabilities. Transportation Research Board. Washington, United States.

Queiroz, M. P. (2003). Análise espacial dos acidentes de trânsito do município de Fortaleza (Dissertação Mestrado). Universidade Federal do Ceará, Fortaleza, Brasil.

Raia Jr., A. A.; Robles, D. G.; Barbato, C. M. L.; Fontana, A. M. (2008). Aspectos de segurança de pedestres em rotatórias urbanas. $2^{2}$ Congresso Luso-Moçambicano de Engenharia. Maputo: CLME.

Silva, A. M. C. B.; Seco, A. J. M. (2004). Dimensionamento de Rotundas. Universidade de Coimbra, Coimbra, Portugal.

Silva, A. M. C. B.; Seco, A. J. M. (2008). Rotundas. Universidade de Coimbra.

Silva, A. C. S. (2002). O pedestre invisível: o caráter de classe da estrutura viária de Campo Grande. (Graduação Comunicação Social/Jornalismo). Universidade Federal do Mato Grosso do Sul, Campo Grande, Brasil.

Sntmu/mc. (2007). PlanMob: Construindo a cidade sustentável. Secretaria Nacional de Transporte e Mobilidade Urbana, Ministério das Cidades, Brasília: SNMTU/MC.

Stone, J. R.; Chae, K. \& Pillalamarri, S. (2002). The Effects of Roundabouts on Pedestrian Safety. The Southeastern Transportation Center Raleigh, North Carolina, United States.

Taekratok, T. (1998). Modern Roundabouts for Oregon. Report no OR-RD-98-17. Oregon Department of Transportation, Research Unit, Salem, Oregon, USA.

Torres, D. (2010). Rotatórias urbanas. Revista Infraestrutura urbana, n.1, p.44-48.

Torquato, R. J. (2011). Percepção de risco e comportamento de pedestres (Dissertação Mestrado). Universidade Federal do Paraná, Curitiba, Brasil.

\section{Abstract}

Among the various techniques to mitigate the pernicious causes from the crossings are in traffic roundabouts, road device better efficiency and lower costs, which are intended to simplify the intersection so that traffic that there interacts have a safe conduct. Although it has been widely used in the Brazilian city traffic, roundabouts prioritize motor vehicle due to lack of infrastructure, whether by choice or lack of technical knowledge, that mainly pedestrian has equal security. To assess what are the indicators that lead to this situation in the devices were used five roundabouts in São José do Rio Preto-five in San Carlos and proposed a confrontation of technical concepts between specialists using the AHP method, literature and reality found in site, to check for possible similarities and differences between definitions, concepts and options. Came to the conclusion that literature and the experts advocate pedestrians as project priority, implementation, infrastructure and maintenance but the devices are not able to safety.

Keywords: Roundabouts, Pedestrians, Traffic Engineering, Geometry Elements, Urban Roads. 